\title{
Metal-Directed Self-Assembly of a Zn"-salpyr Complex into a Supramolecular Vase Structure
}

\author{
Arjan W. Kleij, ${ }^{\dagger, \neq}$ Mark Kuil, ${ }^{\dagger}$ Duncan M. Tooke, ${ }^{\S}$ Anthony L. Spek, ${ }^{\S}$ and Joost N. H. Reek ${ }^{*, \dagger}$ \\ Van't Hoff Institute for Molecular Sciences, University of Amsterdam, Nieuwe Achtergracht 166, \\ 1018 WV Amsterdam, The Netherlands, and Department of Crystal and Structural Chemistry, \\ Bijvoet Center for Biomolecular Research, Utrecht University, Padualaan 8, 3584 CH Utrecht, \\ The Netherlands
}

Received March 2, 2007

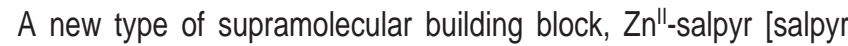
$=N, N$-3-pyridylenebis(salicylideneimine)], is described that contains both a pyridyl donor and a Lewis acidic $\mathrm{Zn}$ "l acceptor site in the salen framework. As a consequence, this building block selforganizes into a stable tetrameric vase structure via cooperative intermolecular $\mathrm{Zn}-\mathrm{N}_{\text {pyr }}$ interactions.

Currently, metalloporphyrins are used as multipurpose molecules because they can be used as catalysts, ${ }^{1}$ chromophores for photochemical processes, ${ }^{2}$ and building blocks for the construction of supramolecular assemblies. ${ }^{3}$ Their multipurpose character makes these building blocks particularly interesting for the creation of functional assemblies. ${ }^{4}$ There are several strategies to assemble porphyrins into higher-ordered structures, but often the pyridine- $\mathrm{M}^{\mathrm{II}}$-porphyrin $(\mathrm{M}=\mathrm{Zn}, \mathrm{Ru}, \mathrm{Co})$ motif is used. ${ }^{5}$ An efficient approach to arrive at well-defined nanosized structures is the use of building blocks that contain both elements of the $\mathrm{M}-\mathrm{N}_{\mathrm{pyr}}$ binding motif. For example, pyridyl-substituted metalloporphyrins ${ }^{6}$ (e.g., see Scheme 1,3 ) give rise to various

* To whom correspondence should be addressed. E-mail: reek@ science.uva.nl. Tel: $+3130-2532538$.

¿ University of Amsterdam.

$\doteqdot$ Current address: Institute of Chemical Research of Catalonia (ICIQ), Av. Paisos Catalans 16, 43007 Tarragona, Spain.

$\S$ Utrecht University.

(1) For some reviews, see: (a) Meunier, B. Chem. Rev. 1992, 92, 1411. (b) Mansuy, D. Coord. Chem. Rev. 1993, 125, 129. (c) Gunter, M. J.; Turner, P. Coord. Chem. Rev. 1991, 108, 115.

(2) For example, see: Gust, D.; Moore, T. A.; Moore, A. L. Acc. Chem. Res. 2001, 34, 40.

(3) For reviews, see: (a) Suslick, K. S.; Rakow, N. A.; Kosal, M. E.; Chou, J. H. J. Porphyrins Phthalocyanines 2000, 4, 407. (b) Bélanger, S.; Keefe, M. H.; Welch, J. L.; Hupp, J. T. Coord. Chem. Rev. 1999, 190-192, 29. (c) Toma, H. E.; Araki, K. Coord. Chem. Rev. 2000, 196, 307.

(4) (a) Drain, C. M.; Lehn, J.-M. J. Chem. Soc., Chem. Commun. 1994 2313. (b) Kroon, J. M.; Südholter, E. J. R.; Schenning, A. P. H. J.; Nolte, R. J. M. Langmuir 1995, 11, 214. (c) Stang, P. J.; Fan, J.; Olenyuk, B. Chem. Commun. 1997, 1453.

(5) (a) Michelsen, U.; Hunter, C. A. Angew. Chem., Int. Ed. 2000, 39, 764. (b) Mackay, L. G.; Wylie, R. S.; Sanders, J. K. M. J. Am. Chem. Soc. 1994, 116, 3141. (c) Okumura, A.; Funatsu, K.; Sasaki, Y.; Imamura, T. Chem. Lett. 1999, 779.

10.1021/ic700408v CCC: $\$ 37.00$ (c) 2007 American Chemical Society Published on Web 06/20/2007
Scheme 1. Synthesis of $\mathrm{Zn}^{\mathrm{II}}$-salen Derivative 1

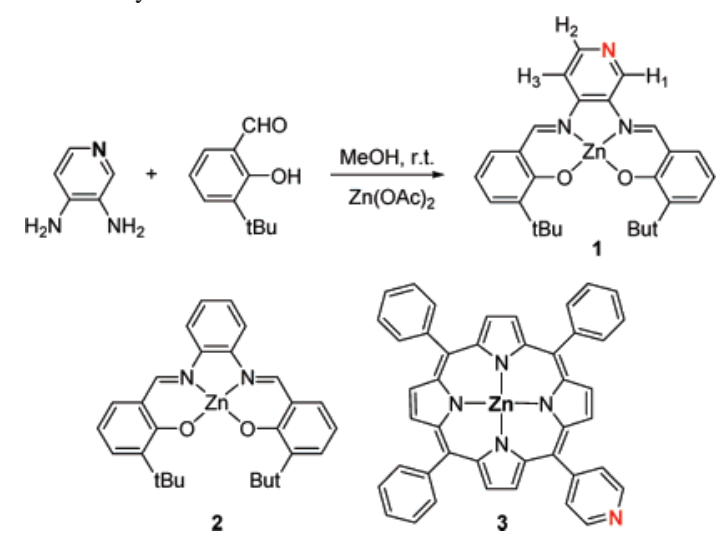

self-assembled structures including molecular squares and loops, ${ }^{7}$ supramolecular boxes,${ }^{8}$ and coordination polymers. ${ }^{9}$ One of the disadvantages of porphyrins is their low-yielding synthesis, especially those with different substituents on the phenyls such as in 3. Metal-salen and -salphen complexes [salphen $=N, N^{\prime}$-phenylenebis(salicylideneimine) $]$ have been intensively explored as interesting alternative building blocks in the area of catalysis. Recently, we showed that pyridine donors are excellent axial ligands for $\mathrm{Zn}^{\mathrm{II}}$-salphen complexes, providing interesting alternative supramolecular building blocks for the construction of new materials and catalysts. ${ }^{10}$

We anticipated that, in analogy to porphyrin chemistry, implementation of both the donor and acceptor within a salen

(6) (a) Chi, X.; Guerin, A. J.; Haycock, R. A.; Hunter, C. A.; Sarson, L. D. J. Chem. Soc., Chem. Commun. 1995, 2567. (b) Imamura, T.; Fukushima, K. Coord. Chem. Rev. 2000, 198, 133. (c) Wojaczyński, J.; Latos-Grażyński, L. Coord. Chem. Rev. 2000, 204, 113. (d) Shachter, A. M.; Fleischer, E. B.; Haltiwanger, R. C. J. Chem. Soc., Chem. Commun. 1988, 960.

(7) (a) Wilson, G. S.; Anderson, H. L. Chem. Commun. 1999, 1539. (b) Fan, J.; Whiteford, J. A.; Olenyuk, B.; Levin, M. D.; Stang, P. J.; Fleischer, E. B. J. Am. Chem. Soc. 1999, 121, 2741. (c) Sun, S.-S.; Stern, C. L.; Nguyen, S. T.; Hupp, J. T. J. Am. Chem. Soc. 2004, 126, 6314.

(8) (a) Hwang, I.-W.; Kamada, T.; Ahn, T. K.; Ko, D. M.; Nakamura, T.; Tsuda, A.; Osaka, A.; Kim, D. J. Am. Chem. Soc. 2004, 126, 16187. (b) Vinodu, M.; Stein, Z.; Goldberg, I. Inorg. Chem. 2004, 43, 7582

(9) (a) Twyman, L. J.; King, A. S. H. Chem. Commun. 2002, 910. (b) Fleischer, E. B.; Shachter, A. M. Inorg. Chem. 1991, 30, 3763.

Inorganic Chemistry, Vol. 46, No. 15, 20075829 


\section{COMMUNICATION}

structure would directly lead to new supramolecular structures formed by self-assembly. ${ }^{6,11}$ Herein, we report the synthesis of a $\mathrm{Zn}^{\mathrm{II}}$-salpyr [salpyr $=N, N^{\prime}$-3-pyridylenebis(salicylideneimine)] building block that contains both a Lewis donor and an acceptor site and, as a consequence, selfassembles into a molecular vase structure. The easy synthesis and subsequent formation of well-defined supramolecular assemblies make this versatile synthon highly useful for salen-based functional materials ${ }^{12,13}$ and an excellent building block next to the porphyrin analogues.

Our recently introduced two-step one-pot procedure ${ }^{10,14}$ provided easy access to the $\mathrm{Zn}^{\mathrm{II}}$-salpyr complex $\mathbf{1}$ (Scheme 1). Complex 1 was isolated as a bright-red solid in high yield (79\%). The structure of $\mathbf{1}$ was confirmed by a combination of spectroscopic and analytical techniques (see the Supporting Information). Crystals of $\mathbf{1}$ suitable for X-ray crystallography were obtained from a hot toluene solution. The structure presented in Figure 1 clearly shows that $\mathbf{1}$ forms a tetrameric assembly $\left([\mathbf{1}]_{4}\right)$ that represents an open vase structure. The tetramer is held together via four $\mathrm{N}_{\mathrm{pyr}}-\mathrm{Zn}$ coordinative interactions. The internal cavity defined by the four salpyr units is filled with disordered toluene solvent molecules (not shown), which were taken into account using the PLATON-SQUEEZE algorithm. ${ }^{15,16}$ Two of the Znsalpyr units have an almost parallel orientation, while the two remaining units are bending outward, giving it the vase shape with a wide and a narrow rim. The vase assembly has an approximate volume of $3100 \AA^{3}$ and diagonal $\mathrm{Zn}-\mathrm{Zn}$ distances of 10.5931(10) and 9.9522(10) A. Further inspection of the tetrameric assembly reveals that one of the $o$-pyridyl protons in $\mathbf{1}$ is positioned inward and is in close contact with one of the phenyl side groups of an adjacent salpyr unit (closest distance around $2.9 \AA$ ). Building block $\mathbf{1}$ is clearly achiral, but the tetramer itself is not because it does not retain the mirror plane present in $\mathbf{1}$. Both enantiomeric forms were found to be present in the solid-state structure. Interestingly, examination of the solid-state structure of $\mathbf{1}$ indicates that the tetrameric structures align to generate channels parallel to the crystallographic $b$ axis (Figure 1b, see also the Supporting Information). Although in the current state the channels are occupied with solvent,

(10) (a) Kleij, A. W.; Kuil, M.; Tooke, D. M.; Lutz, M.; Spek, A. L.; Reek, J. N. H. Chem.-Eur. J. 2005, 11, 4743. (b) Kleij, A. W.; Lutz, M.; Spek, A. L.; van Leeuwen, P. W. N. M.; Reek, J. N. H. Chem. Commun. 2005, 3661. (c) Kleij, A. W.; Kuil, M.; Lutz, M. L.; Tooke, D. M.; Spek, A. L.; Kamer, P. J. C.; van Leeuwen, P. W. N. M.; Reek, J. N. H. Inorg. Chim. Acta 2006, 359, 1807.

(11) For reviews, see: (a) Fujita, M.; Umemoto, K.; Yoshizawa, M.; Fujita, N.; Kusukawa, T.; Biradha, K. Chem. Commun. 2001, 509. (b) Jones, C. J. Chem. Soc. Rev. 1998, 27, 289. (c) Seidel, S. S.; Stang, P. J. Acc. Chem. Res. 2002, 35, 972. (d) Leininger, S.; Olenyuk, B.; Stang, P. J. Chem. Rev. 2000, 100, 853. (e) MacGillivray, L. R.; Atwood, J. L. Angew. Chem., Int. Ed. 1999, 38, 1018. (f) Caulder, D. L.; Raymond, K. N. Acc. Chem. Res. 1999, 32, 975.

(12) (a) Chichak, K.; Branda, N. R. Chem. Commun. 2000, 1211. (b) Chichak, K.; Jacquemard, U.; Branda, N. R. Eur. J. Inorg. Chem. 2002, 357.

(13) Pyridyl-appended salphen ligands have been reported but were, unlike in this work, prepared using a multistep approach. See: Morris, G. A.; Nguyen, S. T. Tetrahedron Lett. 2001, 42, 2093.

(14) Kleij, A. W.; Tooke, D. M.; Spek, A. L.; Reek, J. N. H. Eur. J. Inorg. Chem. 2005, 4626.

(15) Spek, A. L. J. Appl. Crystallogr. 2003, 36, 7.

(16) Spek, A. L.; van der Sluis, P. Acta Crystallogr. 1990, A46, 194. a

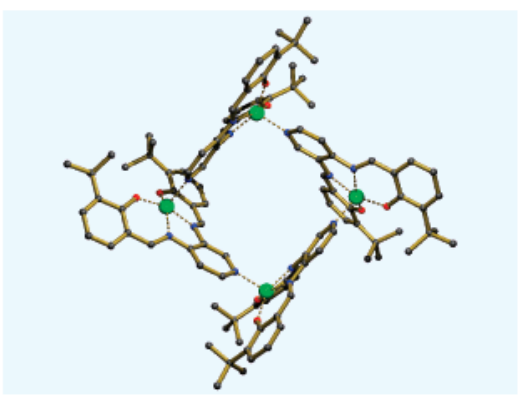

b

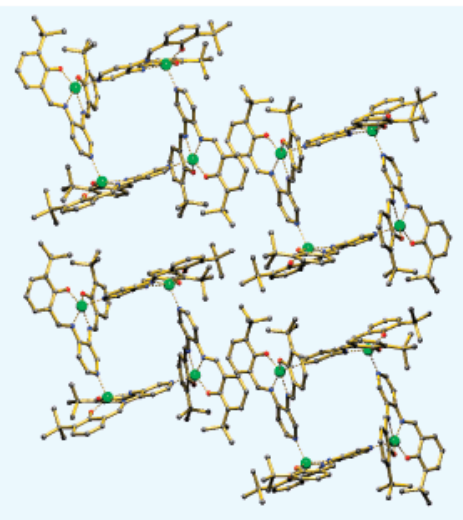

Figure 1. (a) X-ray solid-state structure of $[1]_{4}$. Numbering scheme, Hatoms, and disordered cocrystallized toluene molecules have been omitted for clarity. (b) Parallel alignment of $[\mathbf{1}]_{4}$ assemblies in the solid state, giving rise to channel formation along the crystallographic $b$ axis.

these porous metalloorganic frameworks have recently attracted a great deal of attention because of their potential in crystal engineering and material science. ${ }^{17}$

The ${ }^{1} \mathrm{H}$ NMR spectrum of $[\mathbf{1}]_{4}$ in $\mathrm{C}_{6} \mathrm{D}_{6}$ displays a wellresolved resonance pattern, suggesting the presence of a single and discrete species (Supporting Information). The pyridyl protons (Scheme 1) appear as broadened peaks at $7.84\left(\mathrm{H}_{1}\right), 7.41\left(\mathrm{H}_{2}\right)$, and $5.73 \mathrm{ppm}\left(\mathrm{H}_{3}\right)$ and are significantly shifted upfield. This clearly indicates that the pyridyl unit is engaged in coordination to the $\mathrm{Zn}$ metal center. This particular $\mathrm{Zn}-\mathrm{N}$ interaction was disrupted by the addition of an excess of pyridine- $d_{5}$ to generate the monomeric species 1.pyridine- $d_{5}$ (Supporting Information). The signals for the protons of the pyridyl unit of the salpyr ligand sharpened significantly for the $\mathbf{1} \cdot$ pyridine- $d_{5}$ complex. The line broadening observed for $[\mathbf{1}]_{4}$ indicates that the assembly process reaches the slow-exchange region, which suggests the generation of a discrete assembly. The disassembly of $[\mathbf{1}]_{4}$ also resulted in large changes in the chemical shift for the pyridyl protons, $\mathrm{H}_{1}-\mathrm{H}_{3}$ shifted to 8.36 (s), 8.24 (d), and 6.55 (d) ppm, respectively. The large change in the chemical shift is in line with that of the solid-state structure of $[1]_{4}$, in which the pyridyl protons are in close proximity to the adjacent salpyr units. The pyridyl protons $\mathrm{H}_{2}$ and $\mathrm{H}_{3}$ become particularly shielded $(\Delta \delta \sim 0.8 \mathrm{ppm}$ for both protons compared to the typical shift of $\sim 0.2 \mathrm{ppm}$ for the $o$-pyridyl- $\mathrm{H}$ in pyridine-ligated $\mathrm{Zn}^{\mathrm{II}}$-salphen complexes!) ${ }^{10 a, b}$ upon as-

(17) For interesting reviews, see: (a) Kitagawa, S.; Kitaura, R.; Noro, S.I. Angew. Chem., Int. Ed. 2004, 43, 2335. (b) Barnett, S. A.; Champness, N. R. Coord. Chem. Rev. 2003, 246, 145.

5830 Inorganic Chemistry, Vol. 46, №. 15, 2007 


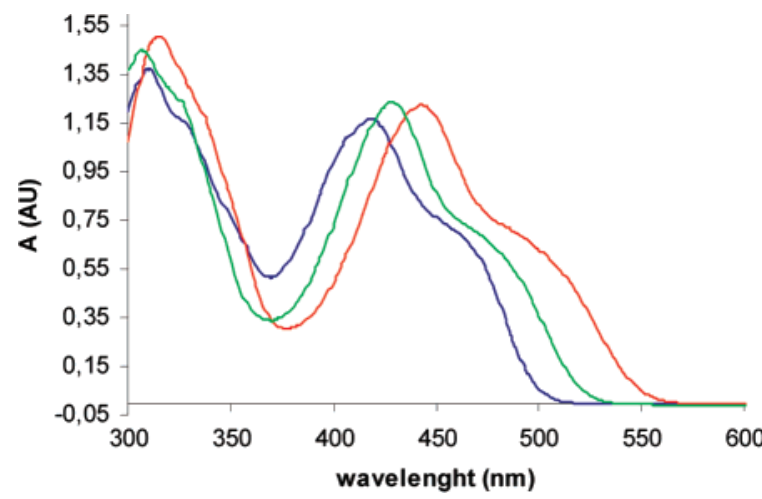

Figure 2. UV-vis spectra recorded for $[\mathbf{1}]_{4}$ (in red), complex $\mathbf{1}$ in the presence of excess of pyridine (in green), and complex $\mathbf{2}$ (in blue).

sembly formation. The ${ }^{1} \mathrm{H}$ NMR analysis of $[1]_{4}$ in $\mathrm{CD}_{2} \mathrm{Cl}_{2}$ also displayed a single and simple resonance pattern with slightly broadened signals but with significantly smaller upfield shifts of the pyridyl protons (Supporting Information). This difference in the upfield shifts can be partially attributed to the shielding effect by the occluded benzene solvent molecules (NMR samples) within the supramolecular structure, similar to that observed in the solid-state structure that contains toluene guests. NMR dilution experiments (up to $1 \times 10^{-3} \mathrm{M}$ ) of $[1]_{4}$ in $\mathrm{C}_{6} \mathrm{D}_{6}$ revealed no change in the resonance pattern, indicating that assembly of $[\mathbf{1}]_{4}$ is the dominant species over a larger concentration region. Additionally, the UV-vis spectrum of $[\mathbf{1}]_{4}$ in toluene remained unchanged at concentrations as low as $10^{-6} \mathrm{M}$. These results suggest the presence of the stable and discrete assembly $[\mathbf{1}]_{4}$ even at concentrations as low as $10^{-6} \mathrm{M}$.

UV-vis spectra of $[1]_{4}\left(5 \times 10^{-5} \mathrm{M} \mathbf{1}\right)$ in toluene showed a red shift compared to its analogue 2 (Figure 2), from $419 \mathrm{~nm}$ for compound $2\left(\epsilon=1.74 \times 10^{4} \mathrm{M}^{-1}\right)$ to $442 \mathrm{~nm}$ for assembly $[\mathbf{1}]_{4}\left(\epsilon=2.21 \times 10^{4} \mathrm{M}^{-1}\right)$. This optical change clearly supports the assembly formation of $[\mathbf{1}]_{4}$ through intermolecular association of the pendant pyridyl groups with the $\mathrm{Zn}^{\mathrm{II}}$ metal centers. Interestingly, $\mathbf{1} \cdot$ pyridine, formed in situ by the addition of excess pyridine to the solution of $[\mathbf{1}]_{4}$, shows a much smaller, more typical, ${ }^{10}$ red shift $\left(\lambda_{\max }=\right.$ $429 \mathrm{~nm}$ compared to $\lambda_{\max }=419 \mathrm{~nm}$ for 2 ) than assembly $[1]_{4}$. Apparently, there is a ground-state interaction between the individual chromophores in assembly $[\mathbf{1}]_{4}$.

The large red shift for $[\mathbf{1}]_{4}$ compared to $\mathbf{1} \cdot$ pyridine allows the competition between the self-association and pyridine coordination to be studied by UV-vis titrations (Figure 3 ). Small amounts of pyridine were added in a stepwise manner to a solution of $[\mathbf{1}]_{4}\left([\mathbf{1}]=3.6 \times 10^{-5} \mathrm{M}\right)$ in toluene, and the absorption at $429 \mathrm{~nm}\left(\lambda_{\max }=1 \cdot\right.$ pyridine $)$ was monitored. The titration curve is substantially different from that expected for a normal 1:1 competition experiment and seems typical of a cooperative binding process. In fact, the sigmoidal-shaped curve of up to 4 equiv is very similar to that found for the $\mathrm{O}_{2}$-binding process to hemoglobin, an allosteric binding process that results in very efficient $\mathrm{O}_{2}$ transport from air, via the lungs and blood, to the cell tissue. ${ }^{18}$ The curve is easily explained in qualitative terms; the first

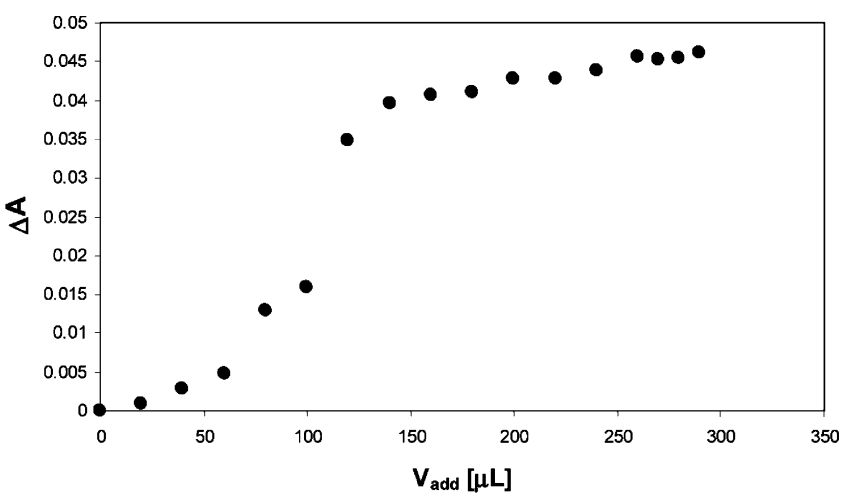

Figure 3. Titration curve of tetrameric $[\mathbf{1}]_{4}$ with pyridine.

salpyr that is removed from the tetrameric structure is attached via two pyridyl-Zn interactions. Therefore, the structure remains rather unaffected in the presence of small amounts of pyridine up to 1 equiv (ratio of $\mathbf{1}$ /pyridine $\leq 1$ ). A further addition of pyridine leads to increasing disruption of the tetrameric structure and the formation of monomeric $\mathbf{1} \cdot$ pyridine. The cooperative binding curve of pyridine to $[\mathbf{1}]_{4}$ is a result of the properties of the assembled host and not of the $\mathrm{Zn}$-pyridine interaction itself because the host changes its structure upon pyridine complexation. Although the titration curve represents the disruption of the tetrameric structure, it clearly reflects that $[\mathbf{1}]_{4}$ is formed by a cooperative binding interaction of the final salpyr closing the square in assembly $[\mathbf{1}]_{4}$.

In summary, we have presented a new supramolecular building block, $\mathrm{Zn}^{\mathrm{II}}$-salpyr complex 1, containing two complementary binding motifs that give rise to cooperative self-assembly into a supramolecular vase structure through $\mathrm{Zn}^{\mathrm{II}}-\mathrm{N}_{\mathrm{pyr}}$ coordination patterns. Such supramolecular systems are highly accessible via these versatile synthons that are easily modified, and this represents an important advantage compared to pyridyl-derived metalloporphyrin systems of type $3{ }^{6 \mathrm{~d}}$ Modification of the $\mathrm{Zn}^{\mathrm{II}}$-salpyr building block $\mathbf{1}$ provides a method to prepare self-assembled vase structures decorated with functional groups. Ideally, the cooperative assembly, or disassembly, of analogues of $[\mathbf{1}]_{4}$ should be combined with an additional function that depends on the assembly status of the building block to arrive at responsive functional materials. Considering the easy access of these building blocks, this next step is realistic, and research along these lines is currently carried out in our laboratory.

Acknowledgment. We thank The Netherlands Organization for Scientific Research (NWO, ViCi program to J.N.H.R.) and the Universities of Amsterdam and Utrecht for financial support.

Supporting Information Available: Synthetic procedures for 1 and 2, NMR spectra recorded in $\mathrm{C}_{6} \mathrm{D}_{6}$ and $\mathrm{CD}_{2} \mathrm{Cl}_{2}$, and an extended packing diagram of $[\mathbf{1}]_{4}$ in the solid state. This material is available free of charge via the Internet at http://pubs.acs.org.

\section{IC700408V}

(18) Imai, K. Allosteric Effects in Hemoglobin; Cambridge University Press: Cambridge, U.K., 1982. 